\title{
responsabilidad y marcas de calidad conferencia pronunciada en Barcelona, el 11 de diciembre de 1974 en el II Congreso Nacional de la Calidad MIGUEL VILA, licenciado en Ciencias Químicas
}

\begin{abstract}
Se reproduce aquí la conferencia pronunciada por el autor en el II Congreso Nacional de la Calidad, en Barcelona (España), en la que se exponen conceptos, proyectos, realizaciones y planes para el futuro, representando las inquietudes del sector, y se transmiten las obras concretas y la filosofía de un grupo de trabajo CIETSID, con la participación del Instituto Eduardo Torroja, CENIM, A.E.C.C., de los organismos oficiales, colegios profesionales, UNESID y fabricantes.
\end{abstract}

El tema que primeramente vamos a abordar en este II Congreso Nacional de la Calidad, dentro del sector Siderúrgico, es:

"Responsabilidad y Marcas de Calidad".

Por la necesaria limitación del tiempo expondremos únicamente: conceptos, proyectos, realizaciones, deseos y aspiraciones; los detalles podrán verse en su día en las publicaciones correspondientes.

Mi agradecimiento a la A.E.C.C. por su siembra de inquietudes, a la organización de este Congreso (Excmo. Ayuntamiento y Cámara de Comercio, Navegación e Industria) por su realización, y a ustedes por acudir, ya que sin la coexistencia de los tres sólo cabría el monólogo, pero deseamos el diálogo.

Deseo aclarar, a priori, que el conferenciante de turno es tan sólo un representante de las inquietudes de un sector

- el de armaduras pasivas para el hormigóny que en lo positivo que pudiere haber transmite las realizaciones y filosofía de un grupo de trabajo CIETSID con participación en el seno del I.E.T.c.c. de: CENIM, A.E.C.C., Administración, colegios profesionales, UNESID y fabricantes.

\section{CALIDAD}

Entendemos la calidad como la adecuación o aptitud al uso, o como el grado de cumplimiento - según define el III PLAN DE DESARROLLO (1) - de las propiedades de un producto, con relación a un conjunto de características a priori especificadas, y determinadas éstas considerando las utilizaciones presumibles del producto.

La calidad debe abarcar el ciclo completo desde la concepción del producto: diseño, adquisición de materiales y equipos, fabricación y utilización.

En la definición de la calidad juega un papel determinante la normalización con sus características de:

- juicio;

- realismo

- asequibilidad técnica y económica;

- conocimiento de la fabricación y sus posibilidades:

- necesidades y aplicaciones;

- condiciones mínimas de seguridad.

Es necesario inculcar la normalización dinámica que recoja las variaciones que la ciencia y la tecnología introducen.

En la constatación de la calidad deben intervenir los usuarios transformadores y los utilizadores últimos.

La consecución de la calidad es una tarea común en el interior de las empresas, con la colaboración activa de todos los elementos humanos; la calidad es más que la existencia de unas técnicas, normas, pliegos, especificaciones, organización.. es una forma de ser, pensar y actuar (2) . 
La correlación entre responsabilidad y calidad, lo es a través de:

- cargo en una obligación;

- parte en una causa;

- seguridad, salud pública;

- deontología profesional.

Sin el hombre no existirían los problemas y sus soluciones.

La economía debe servir al hombre.

No reemplazar la religión por la técnica (3).

Descubrir las leyes inmutables de la materia, no para posesión, sí para el uso del bien común.

La calidad es un condicionamiento de supervivencia de la empresa y en particular de la siderurgia; debemos seguir tomando la iniciativa. La competencia directa estimula la calidad y la productividad, a través de la responsabilidad de persistencia a corto, medio y largo plazo; la competencia indirecta, o de sustitución por otros materiales con su carácter incisivo, nos plantea un reto que no podemos dejar de afrontar.

Estancarse es retroceder y, por ende, el efecto multiplicador de la común ley de los rendimientos decrecientes es inexorable.

La responsabilidad debe ser mucho más que la garantía de un producto determinado; deben ser las del orden legal a escala nacional y mundial y la necesidad de que los productos y servicios sean adecuados para un usuario, que la mayoría de las veces no puede contrastar la adecuación, por falta de medios, tiempo o función industrial distinta.

\section{Surgen las normas de calidades mínimas}

fijadas por la Administración, en razón de la Seguridad o salud pública, de las Asociaciones de defensa del consumidor. Normas básicas y tecnológicas, Manuales de Garantía o Seguridad de la Calidad, Instrucciones, Homologaciones, Agrément, Certificados de idoneidad técnica, de origen industrial, marcas de calidad o conformidad con normas y Marcas nacionales de calidad.

\section{MATERIALES TRADICIONALES}

Un trabajo reciente de Ruiz Duerto, del I.E.T.c.c. (4), distingue en construcción dos tipos de materiales: tradicionales y nuevos o no tradicionales, y contempla la manera de controlar la calidad en obras civiles y edificación.

El término tradicional - continúa el autor-se dirige a los materiales, sistemas o procedimientos de construcción a los que son aplicables las instrucciones, normas, especificaciones, pliegos, códigos de buena práctica... y constituyen la expresión escrita y/o legislación vigente de la sanción experimental de la adecuación.

Respecto a las barras de acero liso o corrugado como armaduras pasivas en España, existe legislación preceptiva a través de las normas correspondientes adaptadas por la Comisión Permanente UNE-MOP (5) (creada para proponer a la superioridad las normas UNE que se consideren de obligado cumplimiento en MOP) e Instrucción Interministerial EH-73 para obras de hormigón en masa o armado vigente a los seis meses de su publicación en el "B. O. E.", diciembre 1973.

El fabricante de armaduras corrugadas (6) (7) debe adoptar:

a) como recomendación, grabados específicos para cada tipo o tensión límite;

b) obligatoriedad de señales de identificación de tipo y marca/factoría, a través de semiótica en bits grabados sobre las barras.

Aprovecho para indicarles que en breve existirá un documento de IRANOR recogiendo nominalmente por marca la semiótica obligatoria;

c) poseer certificados con resultados positivos o suficientes de mínimos de las características de adherencia por unos parámetros y su tolerancia de cifras geométricas (homologación de adherencia) ;

d) certificados positivos de homologación de soldadura para procesos de soldeo determinados y enunciados por el fabricante con expresión del coeficiente de carbono equivalente y su tolerancia de composición química, como 
índice de facilidad/dificultad al empalme por fusión;

e) cumplir los mínimos de cifras resistentes y plásticos y las tolerancias de normas de sección por su responsabilidad en la seguridad;

f) aptitud al ferrallado o conformado de las armaduras;

g) obligación de informar a los consumidores a través de los Certificados de Garantía, de origen industrial, etc., por unidades de fabricación (coladas o lotes para cada uno de los envíos). Entronque con las condiciones generales de venta de productos siderúrgicos [8].

Abandono este campo concreto - calidad de armaduras-, toda vez que el Sr. Calavera les hablará más tarde de ello.

La realización de la norma de este subsector siderúrgico pudo ser efectivo gracias a la conjunción del Departamento de Normalización de UNESID y miembros del grupo de trabajo: expertos, interesados y apasionados por el tema.

\section{MARCAS DE CALIDAD O CONFORMIDAD CON NORMAS}

\section{Legislación previa}

En las jornadas de IRANOR 14-15/II/74 sobre Marca de Calidad, y en su apertura, el Sr. Sistiaga (9) planteaba los hechos cronológicos siguientes:

En la ley de ordenación y defensa de la industria del 24 de noviembre de 1939 aparece la preocupación gubernativa de la calidad, disponiendo que podría concederse oficialmente Marcas de Calidad.

Eran nobles deseos en un marco económico difícil y no pudieron cristalizar.

En la década de los años 50 aparece el Decreto que creó los Materiales Nacionales de Fabricación y de la Calidad.

Tampoco fructificaron.

El Instituto Nacional de Racionalización y Normalización aprobó en 1968 la regulación de las marcas de conformidad a normas UNE (10).
La siembra de las inquietudes de mejora de la calidad para:

- defensa de la competencia,

- por exigencias del consumidor,

- para concurrir a mercados exteriores,

conducen a realidades en el marco de la década de los 70 , tras nuestro take-off económico industrial.

Ejemplos de realidades son (11):

a) DIS-CAL, distintivo de calidad para conglomerantes hidráulicos (cementos) del Ministerio de Industria. Falta de interés activo de los fabricantes. En este caso, en particular, la calidad de las marcas sustituye a las marcas de calidad.

b) CIETAN, aplicable a materiales derivados del cemento. Ya son realidad los de viguetas pretensadas y están en vías de realización los de tubos y baldosas de terrazo.

Un grupo de fabricantes responsables consiguen hacerse oír en los organismos oficiales y en 1966 aparecen disposiciones para intentar obligar a fabricar bien. Decreto de 20 de enero y Legislación complementaria (12).

Aparece VP-71. NORMAS -

AUTOCONTROL - INSPECCIONES -

ESTATUTOS, verdadero sujeto, origen de los posteriores Sellos.

c) CIETSID. Fabricantes de barras corrugadas, principios de 1975, primeros Sellos.

d) CIETFHOP. Fabricantes de hormigón preparado.

e) Grupo Nacional de Industrias del Plástico. Tubos de P.V.C.

f) Decreto $2.714 / 1971$ del 14 de octubre, "B. O. E." núm. 257, del 8 de noviembre de 1971, para puertas planas de madera, señalando preferencias en las obras y adquisiciones que se realicen con fondos públicos; es el horizonte de nuestras aspiraciones: la ratificación por la Administración.

g) Preocupación por la Calidad. El Ministerio de Industria dicta la Orden de 10 de junio de 1971 ( "B. O. E." núm. 149, de 22 de junio), estableciendo 
condiciones para la materia prima y mínimos de control de las industrias dedicadas a la fabricación de barras corrugadas. Obligatoriedad según UNE 36088.

\section{FILOSOFIA DE LA MARCA DE CALIDAD O CONFORMIDAD CON NORMAS}

La norma constituye la definición y evaluación de la calidad de un producto.

La marca NF, establecida en Francia en 1938, nos señala, a través de un artículo de Ms. Thiard (13), de AFNOR, la política de calidad y conformidad con normas de un país.

Para el establecimiento de una marca de conformidad que sustituya, disminuya o complemente la recepción, es necesario el establecimiento de (14):

a) definición específica de la calidad NORMA;

b) reglas y actuaciones de autocontrol por fabricante;

c) inspección por jueces no partes;

d) estatutos;

e) signos distintivos y publicaciones periódicas con expresión de los productos con marca de calidad vigente;

f) legislación positiva, que ratificando un correcto proceder, como defensa del consumidor, estimule a los sectores industriales: con ventajas preferenciales, coeficiente de seguridad de los materiales menores, nivel de intensidad de control menores, económicas, fiscales, etc.

La época de filosofía económica de Santo Tomás de Aquino fue sustituida por la filosofía calvinista del beneficio y constituye uno de los orígenes motores de la sociedad capitalista. Deseamos que el precio no constituya la única decisión de nuestras transacciones comerciales; es necesario, por tanto, dar sentido de utilidad a la mejora de la calidad. Querría desde aquí que llegasen nuestras voces a la Administración.

Las normas de conformidad establecen los contratos siguientes: a) Contrato de carácter jurídico entre fabricante y consumidor; el primero garantiza al segundo que el producto es conforme a NORMAS.

b) Contrato que representa análogamente una relación jurídica entre fabricante y la Marca; el primero reconoce al segundo el derecho a controlar los productos sometidos a conformidad, se somete a las formalidades y conclusiones del control y admite su arbitraje de equidad en el caso de conflicto con el comprador.

c) Contrato moral, sin línea jurídica, entre la Marca y el comprador o consumidor.

Son formas acordes con los clásicos del Derecho Mercantil.

Deseamos destacar que hallarse en posesión de la marca no significa que la calidad de cada una de las unidades de producto esté garantizada por la marca; pero sí garantiza que la fabricación, equipos de control y autocontrol se realiza en conformidad a las normas.

La organización del Sello debe velar por la constancia o permanencia de la calidad; para ello es condición sine qua non que los inspectores del Sello tengan abiertas las puertas a las inspecciones periódicas y aperiódicas.

Los controles de la Marca no son ni control de fabricación, ni de recepción; es un supercontrol o control de los controles efectuados por el fabricante.

En el caso de CIETSID (15), la organización general está constituida por:

- Asamblea general;

- Comisión del Sello;

- Comité ejecutivo,

descansando sobre un reglamento particular que prevé las prácticas de funcionamiento administrativo, técnico y económico, concesión-anulación y sanciones (uso abusivo, publicidad o prácticas fraudulentas).

Trámites: solicitud y concesión:

a) sometimiento estatutos; 
b) ser miembro activo de UNESID ampliando sus obligaciones y ejerciendo sus derechos;

c) trabajar con materia prima homogénea y controlada;

d) existencia de equipos mínimos de control:

e) poseer homologación de adherencia;

f) visita previa de los inspectores respecto a los apartados anteriores c), d) e instalaciones que permitan razonablemente mantener los niveles de calidad y realizar autocontrol, bajo las modalidades por variables y atributos, con expresión gráfica, o por valores o por adjetivos;

g) 6 meses después de la visita previa y con expresión de los resultados de autocontrol suficientes respecto a los valores de límite crítico y zonas de atención, situación del valor característico para $95 \%$ e histograma, el peticionario se encuentra en condiciones de concesión del Sello;

h) someter la documentación de publicidad a la Comisión del Sello;

i) corresponder a los gastos ponderados del Sello.

La práctica enseña que poner en rodaje, en marcha una organización como la comentada presupone del orden de 2 años para la redacción de la norma y 2 años para la implantación y concesión de los primeros Sellos.

Desearía comentar el artículo $50^{\circ}$ del reglamento vigente de CIETSID.

El Sello se concederá, aplicará y, en su caso, retirará conjuntamente e indivisiblemente a todos los aceros corrugados que se ofrezcan al mercado:

a) por un mismo fabricante, aunque sea bajo distinta designación comercial;

b) bajo una misma designación comercial, aunque se produzcan por distintos fabricantes.

\section{Son mecanismos sinceros y auténticos de defensa del consumidor}

Finalmente: la inscripción al club privado del Sello es voluntaria. Aspiramos finalizar con su elevación a Marca Nacional de Calidad según la legislación vigente (Decreto 20 de septiembre de 1952 del Ministerio de Industria), cuando la Administración sancione positivamente nuestras actuaciones.

Gracias, señores, por su atención.

(1) III Plan de Desarrollo para Industrias Siderúrgicas.

(2) M. VILA: I Congreso Nacional de la Calidad

(3) P. CAPANNA: L. Tecnarquia Barral, Barcelona, 1973.

(4) A. RUIZ DUERTO: II Asamblea General del I.E.T.c.c., Madrid, noviembre 1974, pág. 105.

(5) A. BLASCO VILATELA: Primeras Jornadas sobre Marcas de Calidad y Conformidad IRANOR, Madrid, febrero 1974, pág. 135.

(6) Instrucción EH-73.

(7) M. VILA: Loc. cit.

(8) Condiciones Generales de Venta de Productos Siderúrgicos (UNESID).

(9-10) J. M. SISTIAGA: Loc. cit., Iranor, pág. 125.

(11) A. GARCIA MESEGUER: Loc. cit., Iranor, página 149.

(12) J. JORDAR: Loc. cit., Iranor, pág. 131

(13) A. THIARD: Loc. cit., Iranor, pág. 33.

(14) A. GARCIA MESEGUER: II Sesiones Siderúrgicas de UNESID, Madrid, noviembre 1972.

(15) Estatutos Sello de Conformidad CIETSID.

\section{résumé}

Responsabilité et marques

\section{de qualité}

Miguel Vila, ingénieur industriel

On reproduit ici la conférence prononcée par l'auteur au Ile Congrès National de la Qualité, tenu à Barcelone (Espagne), dans laquelle il expose les concepts, projets, realisations et pians pour le futur, représentant les inquietudes du secteur, et sophie d'un groupe de travail CIETSID, avec la participation de I'Institut Eduardo Torroja, CENIM, AECC, des organismes officiels, ordres professionnels, UNESID

\section{summary}

Responsibility and quality marks

Miguel Vila, industrial engineer

This is a reproduction of the lecture held by the author at the II National Congress of Quality in Barcelona, Spain, which gives account of concepts, projects, works and plans for the future, and information is given on completed works and the philo sophy of a Working Group CIETSID, with the participation of Instituto Eduardo Torroja, CENIM, AECC, of the official organisations, professional colleges, UNESID and

\section{zusammenfassung}

Verantwortung und Qualitätsmarken

Miguel Vila, Industrieingenieur

Es wird die von dem Verfasser an dem 1. Nationalen Kongress gehaltene Vorlesung, in Barcelona, Spanien, wiedergeben Zunkunft und die Probleme des Sektors erwant. Die Vorlesung präsentiert weiterhin konkrete Werke und die Philosopie einer Arbeitsgruppe CIETSID, mit der Mitwirkung des Instituts Eduardo Tarroja, CENIM, AECC, der offiziellen Organisationen, Berufshochschulen, UNESID und der Fabrikan- 